\title{
Cardiac surgery in North America and coronavirus disease 2019 (COVID-19): Regional variability in burden and impact
}

Niv Ad, MD, ${ }^{\mathrm{a}, \mathrm{b}}$ Jessica G. Y. Luc, MD, ${ }^{\mathrm{c}}$ and Tom C. Nguyen, MD, ${ }^{\mathrm{d}}$ COVID-19 North American Cardiac Surgery Survey Working Group

\section{ABSTRACT}

Objective: The coronavirus disease 2019 (COVID-19) pandemic has resulted in an increase in hospital resource utilization and the need to defer nonurgent cardiac surgery procedures. The present study aims to report the regional variations of North American adult cardiac surgical case volume and case mix through the first wave of the COVID-19 pandemic.

Methods: A survey was sent to recruit participating adult cardiac surgery centers in North America. Data in regard to changes in institutional and regional cardiac surgical case volume and mix were analyzed.

Results: Our study comprises 67 adult cardiac surgery institutions with diverse geographic distribution across North America, representing annualized case volumes of 60,452 in 2019. Nonurgent surgery was stopped during the month of March 2020 in the majority of centers ( $96 \%$ ), resulting in a decline to $45 \%$ of baseline with significant regional variation. Hospitals with a high burden of hospitalized patients with COVID-19 demonstrated similar trends of decline in total volume as centers in low burden areas. As a proportion of total surgical volume, there was a relative increase of coronary artery bypass grafting surgery (high $+7.2 \%$ vs low $+4.2 \%, P=.550$ ), extracorporeal membrane oxygenation (high $+2.5 \%$ vs low $0.4 \%, P=.328$ ), and heart transplantation (high $+2.7 \%$ vs low $0.4 \%, P=.090$ ), and decline in valvular cases (high $-7.6 \%$ vs low $-2.6 \%, P=.195$ ).

Conclusions: The present study demonstrates the impact of COVID-19 on North American cardiac surgery institutions as well as helps associate region and COVID-19 burden with the impact on cardiac surgery volumes and case mix. ( $\mathrm{J}$ Thorac Cardiovasc Surg 2021;162:893-903)

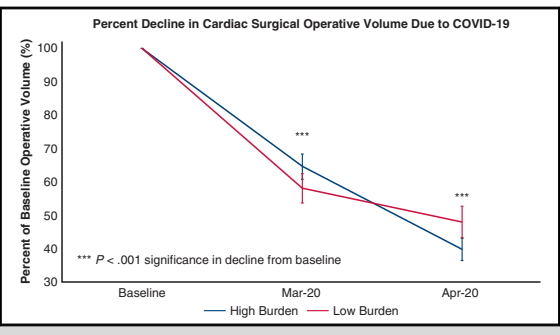

Percent decline in North American cardiac surgica operative volume during the COVID-19 pandemic

CENTRAL MESSAGE

The COVID-19 pandemic has resulted in a decline to $45 \%$ of baseline in cardiac surgery case volumes as institutions defer nonurgent operations, with changes in case mix.

\section{PERSPECTIVE}

We describe the experience of 67 North American adult cardiac surgery institutional experience and demonstrate national and regional variations in response to COVID-19. These findings provide valuable information regarding the volume of patients with procedures deferred to help predict and prepare for the post-COVID-19 surge in cardiac surgery demand.

See Commentaries on pages 904 and 905 .

\footnotetext{
From the a Division of Cardiac Surgery, Department of Surgery, University of Maryland School of Medicine, Baltimore, Md; ' Adventist White Oak Medical Center, Silver Spring, Md; ' $D i v i s i o n$ of Cardiovascular Surgery, Department of Surgery, University of British Columbia, Vancouver, British Columbia, Canada; and ${ }^{\mathrm{d}}$ Department of Cardiothoracic and Vascular Surgery, University of Texas Health Science Center Houston, McGovern Medical School, Houston, Tex.

Drs Ad and Luc contributed equally to this article.

Received for publication May 25, 2020; revisions received June 11, 2020; accepted for publication June 22, 2020; available ahead of print July 2, 2020.

Address for reprints: Niv Ad, MD, Division of Cardiac Surgery, University of Maryland School of Medicine, 110 S Paca St, 7th Floor, Baltimore, MD 21201 (E-mail: nivadmd14@gmail.com).

$0022-5223 / \$ 36.00$

Copyright (c) 2020 by The American Association for Thoracic Surgery

https://doi.org/10.1016/j.jtcvs.2020.06.077
}

The coronavirus disease 2019 (COVID-19) pandemic has had an unprecedented impact on health care, leading to marked global morbidity and mortality. ${ }^{1-8}$ Cardiac surgery is a resource-intensive procedure in regards to intensive care resources. ${ }^{3}$ In the efforts to preserve and redirect limited resources and personnel for the treatment of patients with COVID-19, ${ }^{9}$ nonurgent cardiac surgical services have

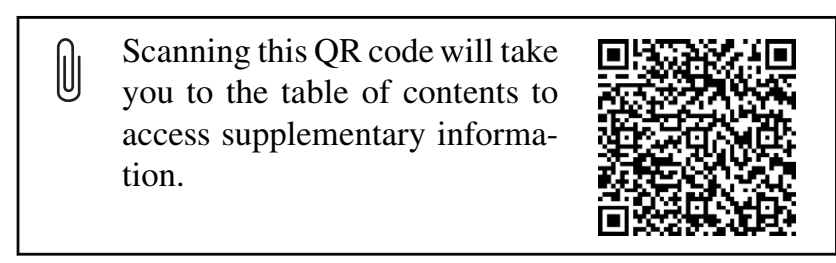




\section{Abbreviations and Acronyms \\ $\mathrm{CABG}=$ coronary artery bypass grafting \\ COVID-19 = coronavirus disease 2019 \\ ECMO = extracorporeal membrane oxygenation \\ STEMI = ST-elevation myocardial infarction}

been deferred per national and regional policies as well as recommendations from the American College of Surgeons and Society of Thoracic Surgeons COVID-19 Taskforce. ${ }^{1}$ Patients with cardiovascular disease, in particular, those with pathology warranting surgical intervention, are often unstable at presentation to the hospital or may become very symptomatic while waiting for their procedure. Therefore, during the pandemic, most operated patients required urgent intervention. ${ }^{10}$ Furthermore, it is anticipated that there may be progressive increase in deferred cases during the pandemic that will require completion within a limited time frame once restrictions ease. ${ }^{11}$

The effect of COVID-19 on North American cardiac surgical volumes, resource management, and outcomes remains unclear. Understanding the impact of COVID-19 on cardiac surgical volumes and the potential regional and institutional differences in crisis management may provide guidance on postpandemic hospital operating capacity required to treat deferred cases. ${ }^{8,11-13}$ In addition, information on the extent of deferred patients can help institutions proactively prepare to reduce the risk of increased morbidity and mortality for patients waiting for procedures. ${ }^{3}$ The present study aims to report the collective North American adult cardiac surgical experience with COVID-19 through the evaluation of changes in cardiac surgical case volume, case mix, and outcomes, as stratified by hospitals with high and low burden of hospitalized patients with COVID-19.

\section{METHODS \\ Study Design}

A web-based survey using the Qualtrics Survey Software (Qualtrics, Provo, Utah) was sent to a representative cardiac surgeon from each major North American adult cardiac surgical center to recruit participating centers (Table E1). The survey was face validated by 2 independent surgeons and sent on April 17, 2020, with discontinuation of survey link access on May 2, 2020. The response rate was 40\% (67/167), representing cardiac surgery annualized case volumes of 60,452 in 2019. The survey tool consisted of multiple-choice and text entry items and was developed by the principal investigators (N.A., J.L., T.N.) with several iterations of internal review and revision, and finally, external feedback solicited from several board-certified actively practicing cardiac surgeons. The survey evaluated institutional annual and monthly cardiac surgical case volume, case mix, COVID-19 cardiac surgical volume and outcomes, hospital capacity, and methods institutions used to optimize COVID-19 surge capacity. The study was approved by the Adventist Health Care institutional review board (protocol no. 2020-09).

\section{Definitions}

Patients confirmed as having COVID-19 were defined as those who received a positive result on their nasopharyngeal swab or any other additional test (eg, endotracheal tube aspirate), whereas those who were classified as suspected as having COVID-19 or persons under investigations were defined as those who were symptomatic or had previous COVID-19 exposure and were awaiting a confirmatory COVID-19 test. Institutions with high burden of COVID-19 were defined as those with $\geq 100$ hospitalized patients with confirmed or suspected COVID-19. Institutions with a low burden of COVID-19 were defined as those with $<100$ hospitalized patients with confirmed or suspected COVID-19. Pre-COVID-19 was defined as before March 1, 2020, with during COVID-19 defined as March 1, 2020, onwards.

\section{Statistical Analyses}

Parametric continuous variables are expressed as mean \pm standard deviation and were compared by the use of the Student $t$ test. Nonparametric continuous variables are expressed as medians (interquartile range) and were compared by the use of the Mann-Whitney $U$ test. Categorical data were expressed as counts and percentages, and the $\chi^{2}$ test was used to analyze differences between groups. Statistical analyses were performed using Stata (Stata Corp, College Station, Tex) with significance at an alpha level of 0.05.

\section{RESULTS \\ Demographics}

Our study comprises 67 adult cardiac surgery institutions, representing 60,452 cardiac surgical operations per year for 2019 with a combined capacity at baseline of 45,417 hospital beds, 6692 intensive care beds, 2664 operating rooms, and a total of 14,640 hospitalized patients with confirmed or suspected COVID-19. Institution geographic distribution and burden of hospitalized patients with confirmed or suspected COVID-19 are shown in Figure 1, with $22(33 \%)$ institutions categorized as having a high and $45(67 \%)$ with a low burden of hospitalized patients with COVID-19. Institution characteristics stratified by geographic region are shown in Tables 1 and 2. Academic centers comprised the majority $(\mathrm{n}=53,79 \%)$, with institutions with a high burden of COVID-19 more likely to be academic centers (high burden $91 \%$ vs low burden $48 \%, P=.003$ ) and to be larger institutions in terms of hospital beds (high burden 916 vs low burden 561, $P=.009$ ), intensive care unit beds (high burden 163 vs low burden $69, P=.003$ ), and operating room capacity (high burden 55 vs low burden $32, P=.043$ ) (Table 3). All institutions reported to have curtailed nonurgent cardiac surgical operations, with the majority having instituted these policies between March 15 and 31, $2020(\mathrm{n}=48,72 \%)$, followed by March 1 to $14,2020(\mathrm{n}=15,22 \%)$ and the remaining April 1, 2020, onwards $(n=4,6 \%)$ (Table 2$)$.

\section{Hospital Resources and Strain of COVID-19 on Health Care System}

The majority of centers have converted medical wards to COVID-19-treating areas (70\%), followed by surgical wards $(34 \%)$, cardiac surgical intensive care units $(28 \%)$, convention centers or public facilities $(21 \%)$, operating rooms $(15 \%)$, ground-up construction with tents or 
Western Canada

Participating Cardiac Surgery Institutions $(n)=8$ Hospitalized COVID Positive/Suspected $(n)=135$ Hospital Beds $(n)=4706$

\section{USA: West}

Participating Cardiac Surgery Institutions $(n)=9$ Hospitalized COVID Positive/Suspected $(n)=461$ Hospital Beds $(n)=4600$
USA: Southwest

Participating Cardiac Surgery Institutions $(n)=7$

Hospitalized COVID Positive/Suspected $(n)=4309$

Hospital Beds $(n)=7835$

A

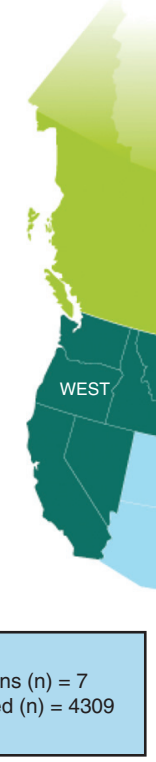

USA: Midwest

Participating Cardiac Surgery Institutions $(n)=7$

Hospitalized COVID Positive/Suspected $(n)=1146$

Hospital Beds $(n)=5404$
USA: Southeast

Participating Cardiac Surgery Institutions $(n)=12$

Hospitalized COVID Positive/Suspected $(n)=1404$ Hospital Beds $(n)=8746$

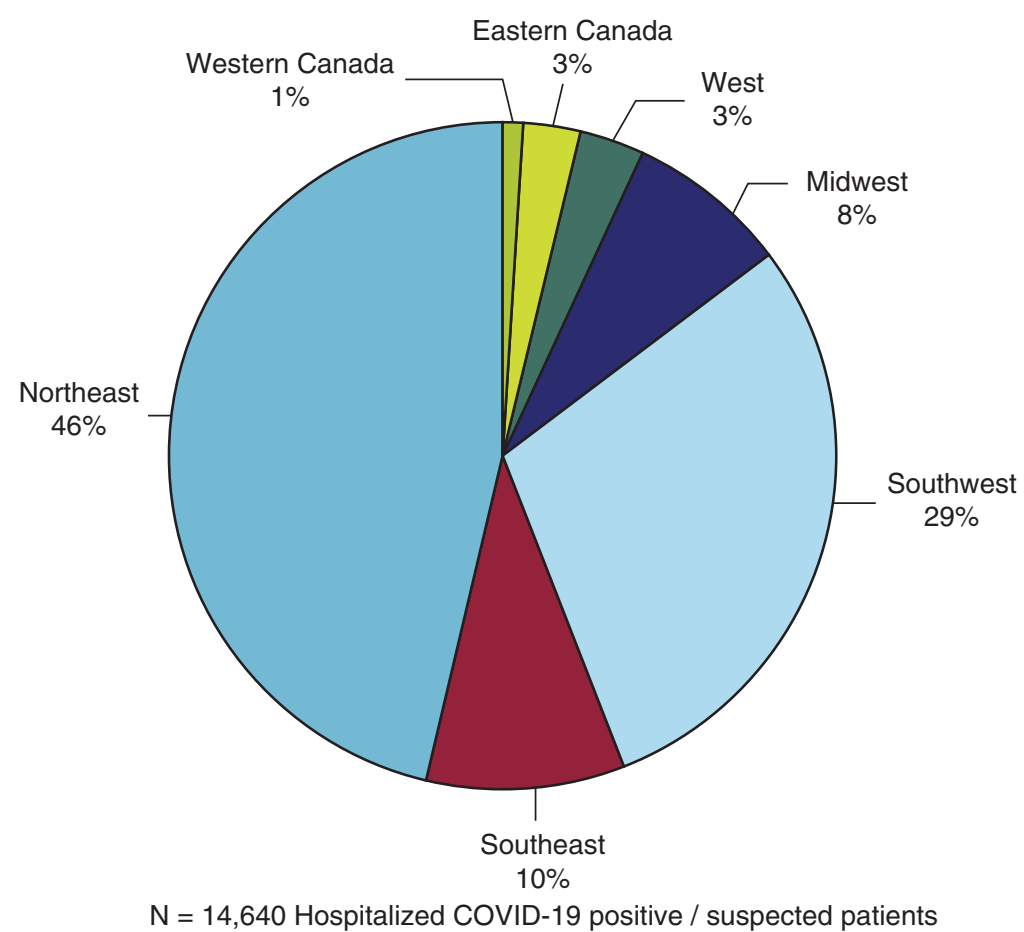

B

FIGURE 1. A, Geographic distribution of institutions; B, proportion of total hospitalized patients with COVID-19 of institutions for each region; and C, proportion of hospitalized patients with COVID-19 to total number of hospital beds for each region. COVID-19, Coronavirus disease 2019.

buildings (13\%), and cardiovascular care units $(7 \%)$. Overall, a minority of cardiac surgeons $(25 \%)$ and trainees $(28 \%)$ required redeployment to alternative duties (Table
2). Table 2 demonstrates the regional variation in increased conversion of alternative locations to COVID-19-treating facilities and redeployment of surgeons and trainees, with 


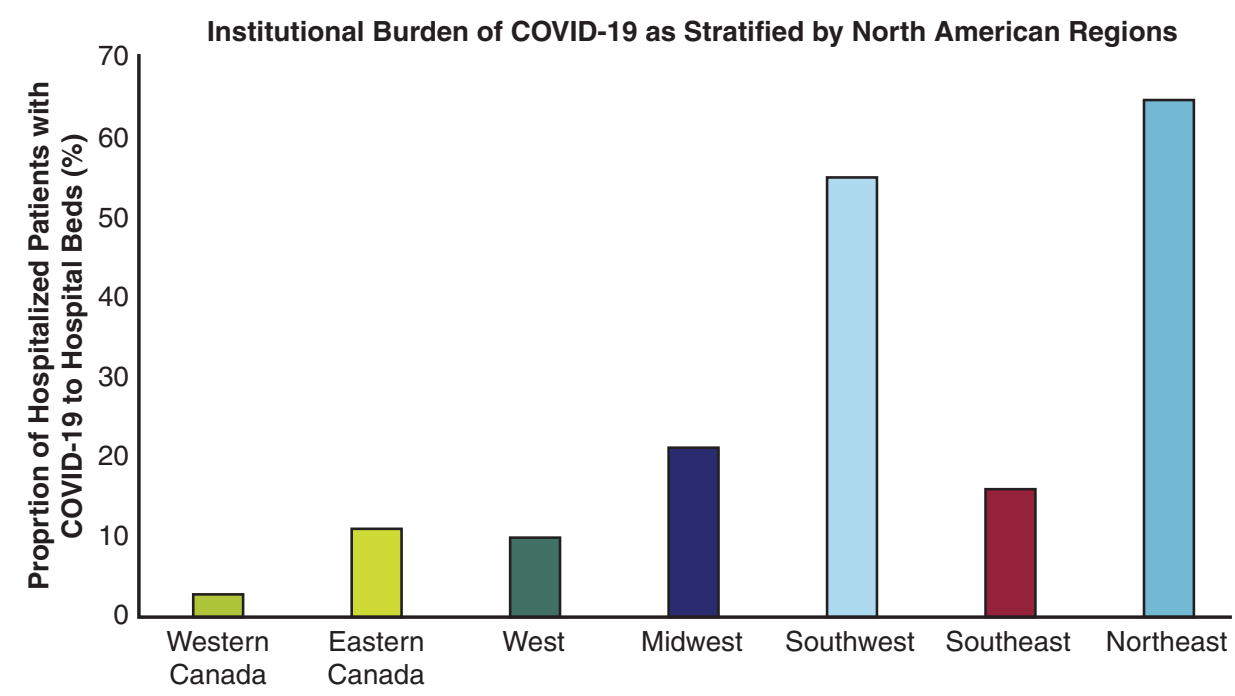

C

FIGURE 1. (Continued).

the greatest proportion of institutions located in the Northeast region of the United States, which also has the greatest burden of COVID-19. When stratified by burden of hospitalized patients with COVID-19, institutions with high burden were more likely to require conversion of alternative locations to COVID-19-treating areas $(P=.020)$ and redeployment of surgeons (high burden $59 \%$ vs low burden $9 \%$, $P=.001$ ) and trainees (high burden $68 \%$ vs low burden $9 \%, P=.001$ ) to alternative duties (Table 3 ).

\section{Effect of COVID-19 Burden on Adult Cardiac Surgery Case Volumes}

Hospital case volumes for adult cardiac surgery declined to $60 \%$ of baseline in March 2020 and then to $45 \%$ of baseline in April 2020 (for all institutions combined-baseline 5354 vs March 3061 vs April 2356 cases per month), with national and regional variations. The decline was greatest in adult cardiac surgery case volumes corresponding to baseline activity, in the Northeast region of the United States in April 2020 (United States: Northeast 36\% of baseline [ $10 \%-69 \%$ ], Southeast $50 \%$ of baseline [25\%-84\%], Southwest $37 \%$ of baseline [ $8 \%-82 \%$ ], Midwest $39 \%$ of baseline [20\%-70\%], West $46 \%$ of baseline [21\%-73\%]; Canada: Eastern $51 \%$ of baseline [12\%-94\%], Western $62 \%$ of baseline [35\%-90\%]) (Figure 2, $A$ ). Institutions with high COVID-19 burden experienced a greater decline in operative volume from baseline in April 2020, which was not significant (high burden $40 \%$ of baseline [12\%-70\%] vs low burden $48 \%$ of baseline [8\%-90\%]) (Figure 2, B).

\section{Effect of COVID-19 on Adult Cardiac Surgery Case Mix}

Cardiac surgery case mix pre-COVID-19 as compared with during COVID-19 is shown in Figure 3, A. An overall increase in the proportion of coronary artery bypass grafting (CABG) surgeries performed during COVID-19 (during $47 \%$ vs pre $41 \%$ ) was observed, with a corresponding decline in valvular cases, with isolated valve surgery (during $23 \%$ vs pre $27 \%$ ) and CABG combined with valve surgery (during $8 \%$ vs pre $12 \%$ ). Institutions with high COVID-19 burden had nonsignificant trends toward a greater proportion of operative cases as $\mathrm{CABG}$ (high burden $+7.2 \%$ vs low burden $+4.2 \%, P=.550$ ), extracorporeal membrane oxygenation (ECMO) (high burden $+2.5 \%$ vs low burden $0.4 \%, P=.328$ ), and heart transplantation (high burden $+2.7 \%$ vs low burden $0.4 \%, P=.090$ ), probably due to the fact that those are usually urgent or emergent, with a nonsignificant lower proportion of valvular cases (high burden $-7.6 \%$ vs low burden $-2.6 \%$, $P=.195$ ) and aortic surgery (high burden $-3.5 \%$ vs low burden $-1.0 \%, P=.328$ ), although the overall number of cardiac surgical case volume during COVID-19 was significantly declined compared with baseline (Figure 3, B, and Figure 4).

\section{Preoperative Testing Practices for COVID-19}

The majority of institutions required COVID-19 testing of all cardiac surgical patients preoperatively for COVID$19(\mathrm{n}=40,60 \%)$, with a minority requiring COVID-19 testing of all cardiac surgical emergency patients for COVID-19 as well $(\mathrm{n}=27,40 \%)$, with national and regional variations reflective of COVID-19 level of burden (Table 2).

\section{Modality of Follow-up for Cardiac Surgical Patients}

Recognizing the potential deleterious impact of delayed cardiac surgical operations to conserve hospital resources and personnel for the treatment of patients with COVID-19, 
TABLE 1. Institutional pre- and during COVID characteristics

\begin{tabular}{|c|c|c|c|c|c|c|c|c|}
\hline & \multicolumn{5}{|c|}{ United States } & \multicolumn{2}{|c|}{ Canada } & \multirow[b]{2}{*}{$\begin{array}{c}\text { All } \\
(\mathbf{n}=\mathbf{6 7})\end{array}$} \\
\hline & $\begin{array}{l}\text { Northeast } \\
(\mathbf{n}=\mathbf{1 5})\end{array}$ & $\begin{array}{l}\text { Southeast } \\
(\mathrm{n}=12)\end{array}$ & $\begin{array}{l}\text { Southwest } \\
(\mathbf{n}=7)\end{array}$ & $\begin{array}{l}\text { Midwest } \\
(\mathbf{n}=7)\end{array}$ & $\begin{array}{c}\text { West } \\
(\mathbf{n}=9)\end{array}$ & $\begin{array}{l}\text { Eastern } \\
(\mathbf{n}=9)\end{array}$ & $\begin{array}{c}\text { Western } \\
(\mathbf{n}=\mathbf{8})\end{array}$ & \\
\hline \multicolumn{9}{|c|}{$\begin{array}{l}\text { Institution } \\
\qquad \text { characteristics, } \mathrm{n}\end{array}$} \\
\hline $\begin{array}{l}\text { Annual pump } \\
\text { volume }\end{array}$ & $959.3 \pm 449.5$ & $632.2 \pm 323.0$ & $700.3 \pm 467.5$ & $1258.7 \pm 1007.6$ & $567.6 \pm 453.7$ & $1216.8 \pm 529.5$ & $1088.1 \pm 498.2$ & $902.3 \pm 567.8$ \\
\hline Hospital beds & $697.7 \pm 341.9$ & $728.8 \pm 240.5$ & $1119.3 \pm 1293.3$ & $772.0 \pm 574.3$ & $511.1 \pm 259.2$ & $406.7 \pm 201.4$ & $588.3 \pm 329.8$ & $677.9 \pm 527.3$ \\
\hline ICU beds & $105.0 \pm 70.9$ & $113.6 \pm 67.9$ & $228.4 \pm 339.2$ & $94.4 \pm 64.1$ & $77.3 \pm 58.8$ & $52.0 \pm 25.1$ & $41.3 \pm 21.4$ & $99.9 \pm 125.7$ \\
\hline Operating rooms & $39.5 \pm 19.6$ & $32.3 \pm 11.0$ & $99.6 \pm 105.6$ & $55.4 \pm 47.9$ & $32.7 \pm 19.0$ & $21.0 \pm 14.0$ & $14.5 \pm 7.0$ & $39.8 \pm 44.1$ \\
\hline $\begin{array}{l}\text { COVID-19- } \\
\text { confirmed } \\
\text { patients }\end{array}$ & $929.6 \pm 422.3$ & $118.6 \pm 70.3$ & $190.6 \pm 363.1$ & $94.1 \pm 57.4$ & $35.1 \pm 42.5$ & $24.8 \pm 30.2$ & $13.8 \pm 15.2$ & $146.6 \pm 472.2$ \\
\hline $\begin{array}{l}\text { COVID-19- } \\
\text { suspected } \\
\text { patients }\end{array}$ & $29.4 \pm 32.1$ & $46.8 \pm 96.9$ & $425.0 \pm 929.9$ & $69.6 \pm 95.0$ & $16.1 \pm 14.3$ & $20.7 \pm 20.6$ & $3.1 \pm 5.6$ & $71.9 \pm 310.5$ \\
\hline \multicolumn{9}{|c|}{$\begin{array}{l}\text { Case distribution pre- } \\
\text { COVID-19, \% }\end{array}$} \\
\hline Valve & $26.6 \pm 9.7$ & $31.7 \pm 14.9$ & $22.4 \pm 9.6$ & $26.6 \pm 13.4$ & $25.2 \pm 10.5$ & $27.9 \pm 7.9$ & $22.9 \pm 5.3$ & $26.6 \pm 10.7$ \\
\hline Valve + CABG & $12.6 \pm 6.2$ & $10.3 \pm 5.7$ & $10.0 \pm 4.1$ & $10.2 \pm 3.9$ & $16.2 \pm 7.4$ & $10.3 \pm 4.7$ & $13.6 \pm 6.1$ & $12.0 \pm 5.8$ \\
\hline CABG & $40.3 \pm 19.0$ & $37.8 \pm 23.9$ & $40.0 \pm 25.4$ & $33.6 \pm 14.3$ & $38.1 \pm 20.2$ & $47.8 \pm 10.9$ & $45.5 \pm 11.4$ & $40.5 \pm 18.5$ \\
\hline Aortic surgery & $12.1 \pm 9.0$ & $10.5 \pm 7.8$ & $14.4 \pm 12.8$ & $13.0 \pm 6.3$ & $16.8 \pm 11.2$ & $9.9 \pm 4.9$ & $9.2 \pm 5.5$ & $12.1 \pm 8.5$ \\
\hline ECMO/MCS & $3.6 \pm 4.1$ & $2.8 \pm 3.3$ & $4.4 \pm 5.3$ & $6.8 \pm 6.4$ & $2.0 \pm 3.5$ & $1.6 \pm 1.9$ & $2.8 \pm 2.4$ & $3.3 \pm 4.0$ \\
\hline Heart transplant & $1.2 \pm 1.9$ & $4.3 \pm 7.3$ & $2.6 \pm 2.1$ & $2.3 \pm 2.8$ & $1.7 \pm 3.5$ & $1.2 \pm 1.8$ & $1.1 \pm 2.2$ & $2.1 \pm 3.8$ \\
\hline Other & $1.2 \pm 1.9$ & $4.3 \pm 7.3$ & $2.6 \pm 2.1$ & $2.3 \pm 2.8$ & $1.7 \pm 3.5$ & $1.2 \pm 1.8$ & $1.1 \pm 2.2$ & $2.1 \pm 3.8$ \\
\hline \multicolumn{9}{|l|}{$\begin{array}{l}\text { Case distribution } \\
\text { during } \\
\text { COVID-19, \% }\end{array}$} \\
\hline Valve & $22.0 \pm 18.7$ & $25.5 \pm 17.3$ & $18.1 \pm 11.2$ & $21.8 \pm 13.9$ & $20.6 \pm 17.9$ & $28.0 \pm 11.5$ & $20.8 \pm 8.6$ & $22.7 \pm 14.9$ \\
\hline Valve + CABG & $6.4 \pm 6.1$ & $7.7 \pm 6.0$ & $3.6 \pm 4.2$ & $6.3 \pm 9.7$ & $9.1 \pm 9.7$ & $10.3 \pm 7.4$ & $15.3 \pm 12.8$ & $8.3 \pm 8.4$ \\
\hline CABG & $42.0 \pm 27.3$ & $42.8 \pm 28.3$ & $38.6 \pm 33.0$ & $47.0 \pm 23.4$ & $52.2 \pm 33.5$ & $53.9 \pm 13.9$ & $51.4 \pm 21.3$ & $46.5 \pm 26.0$ \\
\hline Aortic surgery & $11.8 \pm 14.7$ & $8.3 \pm 7.1$ & $18.0 \pm 19.7$ & $10.4 \pm 5.1$ & $13.9 \pm 25.7$ & $4.9 \pm 5.0$ & $7.4 \pm 6.0$ & $10.46 \pm 14.0$ \\
\hline ECMO/MCS & $5.4 \pm 6.7$ & $5.8 \pm 7.8$ & $14.7 \pm 19.3$ & $10.2 \pm 7.5$ & $0.9 \pm 1.8$ & $2.6 \pm 3.5$ & $1.0 \pm 1.5$ & $5.3 \pm 8.9$ \\
\hline Heart transplant & $4.0 \pm 8.1$ & $7.9 \pm 12.1$ & $1.9 \pm 3.3$ & $3.8 \pm 6.0$ & $2.2 \pm 6.7$ & $0.3 \pm 1.0$ & $0.8 \pm 1.8$ & $3.3 \pm 7.4$ \\
\hline Other & $8.4 \pm 26.5$ & $2.1 \pm 5.8$ & $5.1 \pm 8.6$ & $0.5 \pm 1.2$ & $1.1 \pm 3.3$ & $0.0 \pm 0.0$ & $3.5 \pm 8.7$ & $3.4 \pm 13.2$ \\
\hline
\end{tabular}

ICU, Intensive care unit; COVID-19, coronavirus disease 2019; $C A B G$, coronary artery bypass grafting surgery; $E C M O$, extracorporeal membrane oxygenation; $M C S$, mechanical circulatory support.

the majority of institutions have some mechanism of allowing preoperative cardiac surgical patients to seek expert opinion without the need to venture into the emergency department $(82 \%)$. Of those institutions with this mechanism for patients to seek help, the majority of modalities were follow-up as needed by providing patients with a contact number to reach out to if there are any concerns $(85 \%)$, whereas some institutions proactively reached out to deferred patients every 1 to 2 weeks to monitor a patient's cardiovascular symptoms $(15 \%)$ (Table 2). National and regional variations existed in allowing a mechanism for preoperative cardiac surgical patients to seek care without going to the emergency department, with fewer institutions in the Northeastern United States $(60 \%)$ and Eastern Canada (78\%) having such mechanisms in place. Importantly, these were associated with cardiac surgeon regional differences in the use of telemedicine, with telemedicine used in only $27 \%$ of institutions in the Northeastern United States and 22\% of institutions in Eastern Canada (Table 2). This is further corroborated by institutions with high COVID-19 burden being less likely to use telemedicine than those with low COVID-19 burden (high $77 \%$ vs low $98 \%, P=.012$ ) (Table 3).

\section{Outcomes of Patients With COVID-19 Who Underwent Cardiac Surgical Operations}

Among all institutions combined, there were a total of 9820 patients hospitalized with confirmed COVID-19 and 4820 with suspected COVID-19 identified at the reporting centers. Thirteen patients with known COVID-19 infection underwent cardiac surgical operations, with $1(8 \%)$ death. A total of 65 patients with suspected COVID-19 underwent cardiac surgical operations, with $5(8 \%)$ mortalities. Cumulatively, there were 131 patients $(1 \%$ of all patients with COVID-19 hospitalized) who were reported to require 
TABLE 2. Institutional responses to COVID-19

\begin{tabular}{|c|c|c|c|c|c|c|c|c|}
\hline & \multicolumn{5}{|c|}{ United States } & \multicolumn{2}{|c|}{ Canada } & \multirow[b]{2}{*}{$\begin{array}{c}\text { All } \\
(\mathbf{n}=67\end{array}$} \\
\hline & $\begin{array}{l}\text { Northeast } \\
(\mathbf{n}=15)\end{array}$ & $\begin{array}{c}\text { Southeast } \\
(\mathrm{n}=12)\end{array}$ & $\begin{array}{c}\text { Southwest } \\
(\mathrm{n}=7)\end{array}$ & $\begin{array}{c}\text { Midwest } \\
(n=7)\end{array}$ & $\begin{array}{c}\text { West } \\
(\mathbf{n}=9)\end{array}$ & $\begin{array}{l}\text { Eastern } \\
(\mathbf{n}=9)\end{array}$ & $\begin{array}{l}\text { Western } \\
(\mathbf{n}=\mathbf{8})\end{array}$ & \\
\hline \multicolumn{9}{|l|}{ Dates institutions halted elective cases, $\mathrm{n}(\%)$} \\
\hline March 1-14, 2020 & $4(27)$ & $3(25)$ & $1(14)$ & $0(0)$ & $5(56)$ & $0(0)$ & $2(25)$ & $15(22)$ \\
\hline March 15-31, 2020 & $11(73)$ & $9(75)$ & $5(72)$ & $6(86)$ & $3(33)$ & $8(89)$ & $6(75)$ & $48(72)$ \\
\hline April 1, 2020 onwards & $0(0)$ & $0(0)$ & $1(14)$ & $1(14)$ & $1(11)$ & $1(11)$ & $0(0)$ & $4(6)$ \\
\hline \multicolumn{9}{|c|}{$\begin{array}{l}\text { Required conversion of the following locations to } \\
\text { treating areas for patients with COVID-19, } \mathrm{n}(\%)\end{array}$} \\
\hline None & $0(0)$ & $4(33)$ & $1(14)$ & $2(29)$ & $3(33)$ & $1(11)$ & $2(25)$ & $13(19)$ \\
\hline CSICU & $9(60)$ & $2(17)$ & $0(0)$ & $0(0)$ & $2(22)$ & $5(56)$ & $1(13)$ & $19(28)$ \\
\hline Operating room & $6(40)$ & $1(8)$ & $0(0)$ & $0(0)$ & $0(0)$ & $1(11)$ & $2(25)$ & $10(15)$ \\
\hline Surgical wards & $12(80)$ & $2(17)$ & $2(29)$ & $4(57)$ & $0(0)$ & $3(33)$ & $0(0)$ & $23(34)$ \\
\hline Medical wards & $14(93)$ & $6(50)$ & $5(71)$ & $5(71)$ & $5(56)$ & $7(78)$ & $5(63)$ & $47(70)$ \\
\hline Convention centers/public facilities & $5(33)$ & $2(17)$ & $0(0)$ & $1(14)$ & $1(11)$ & $3(33)$ & $2(25)$ & $14(21)$ \\
\hline Ground construction of tents/buildings & $4(27)$ & $3(25)$ & $0(0)$ & $1(14)$ & $1(11)$ & $0(0)$ & $0(0)$ & $9(13)$ \\
\hline $\mathrm{CCU}$ & $1(7)$ & $0(0)$ & $1(14)$ & $0(0)$ & $1(11)$ & $0(0)$ & $2(25)$ & $5(7)$ \\
\hline \multicolumn{9}{|l|}{$\begin{array}{l}\text { Redeployed the following members of cardiac } \\
\quad \text { surgical teams, n (\%) }\end{array}$} \\
\hline Cardiac surgeon & $9(60)$ & $2(17)$ & $2(29)$ & $1(14)$ & $2(22)$ & $1(11)$ & $0(0)$ & $17(25)$ \\
\hline Trainees & $12(80)$ & $1(8)$ & $3(43)$ & $0(0)$ & $1(11)$ & $1(11)$ & $1(13)$ & $19(28)$ \\
\hline \multicolumn{9}{|c|}{$\begin{array}{l}\text { Routinely screen with COVID-19 test the following } \\
\text { individuals for COVID-19 before cardiac surgery, } \mathrm{n}(\%)\end{array}$} \\
\hline All cardiac surgery patients & $12(80)$ & $7(58)$ & $4(57)$ & $6(86)$ & $5(56)$ & $3(33)$ & $3(38)$ & $40(60)$ \\
\hline All emergency cardiac surgical patients & $8(53)$ & $7(58)$ & $2(29)$ & $1(14)$ & $3(33)$ & $4(44)$ & $2(25)$ & $27(40)$ \\
\hline Family members of cardiac surgical patients & $1(7)$ & $0(0)$ & $0(0)$ & $0(0)$ & $0(0)$ & $1(11)$ & $0(0)$ & $2(3)$ \\
\hline \multicolumn{9}{|l|}{$\begin{array}{l}\text { Mechanism exists for patients on waiting list to } \\
\text { seek care without going to ED, } \mathrm{n}(\%)\end{array}$} \\
\hline Yes (total) & $9(60)$ & $10(83)$ & $6(86)$ & $7(100)$ & $8(89)$ & $7(78)$ & $8(100)$ & $55(82)$ \\
\hline \multicolumn{9}{|l|}{ Of those with follow-up } \\
\hline As needed & $8(89)$ & $8(80)$ & $6(100)$ & $6(86)$ & $8(100)$ & $5(71)$ & $6(75)$ & $47(85)$ \\
\hline Reach out weekly/biweekly & $1(11)$ & $2(20)$ & $0(0)$ & $1(14)$ & $0(0)$ & $2(29)$ & $2(25)$ & $8(15)$ \\
\hline Use of telemedicine during COVID-19, n (\%) & $11(73)$ & $12(100)$ & $7(100)$ & $7(100)$ & $9(100)$ & $7(78)$ & $8(100)$ & $61(91)$ \\
\hline
\end{tabular}

COVID-19, Coronavirus disease 2019; CSICU, cardiac surgery intensive care unit; $C C U$, cardiovascular care unit; $E D$, emergency department.

ECMO for cardiorespiratory failure, of whom $24(18 \%)$ died, and others either remained on ECMO at time of survey or survived.

\section{DISCUSSION}

With more than 4 million cases worldwide at the time of publication, the COVID-19 pandemic presents a public health crisis that challenges the availability of health care personnel and resources. ${ }^{12}$ The impact of COVID-19 has been felt differently across the cardiovascular community at the national and regional levels due in part to differences in prevalence of infection rates and the social and health care system response. ${ }^{14}$

In this comprehensive survey report of the effect of COVID-19 on cardiac surgical institutions in North America with diverse geographic distribution, we demonstrate that cardiac surgical case volumes have declined to $45 \%$ of baseline following COVID-19 with national and regional variation. Interestingly, the trend of decline in the number of cases was of the same for institutions that were in high COVID-19 burden areas compared with those in lowburden areas, indicating a consistent response from institutions in the preparation or confrontation with COVID-19. Institutions with high COVID-19 burden had significant decline in total case volume, with change in case mix, that did not meet statistical significance, largely providing urgent or emergent care for procedures, such as CABG, ECMO, and heart transplantations, rather than valvular and aortic surgical cases.

Operative outcomes of patients with COVID-19 undergoing a cardiac surgical procedure remains unknown. Pooling the collective experience of 67 North American centers in this study, we demonstrate that overall, unadjusted mortality rates for patients with confirmed or suspected COVID19 who underwent cardiac surgical operations was $8 \%$. Furthermore, we report the combined North American 
TABLE 3. Institutional characteristics and responses to COVID-19, stratified by high COVID-19 versus low COVID-19 hospitalization burden

\begin{tabular}{|c|c|c|c|}
\hline & High burden $(n=22)$ & Low burden $(n=45)$ & $P$ value \\
\hline \multicolumn{4}{|l|}{ Institution characteristics, $\mathrm{n}$} \\
\hline Annual pump volume & $984.4 \pm 414.6$ & $823.7 \pm 650.1$ & .294 \\
\hline Hospital beds & $916.4 \pm 746.6$ & $561.2 \pm 329.6$ & .009 \\
\hline ICU beds & $163.0 \pm 196.6$ & $69.0 \pm 48.0$ & .003 \\
\hline Operating rooms & $55.3 \pm 36.7$ & $32.2 \pm 45.7$ & .043 \\
\hline COVID-19-confirmed patients & $400.0 \pm 774.4$ & $22.7 \pm 20.5$ & .002 \\
\hline COVID-19-suspected patients & $192.0 \pm 529.1$ & $13.2 \pm 15.3$ & .026 \\
\hline \multicolumn{4}{|l|}{ Change in case-distribution (during to pre-COVID-19), \% } \\
\hline Valve & $-7.6 \pm 20.7$ & $-2.6 \pm 11.1$ & .195 \\
\hline Valve + CABG & $-3.9 \pm 8.1$ & $-3.6 \pm 8.1$ & .855 \\
\hline CABG & $7.2 \pm 23.0$ & $4.2 \pm 16.6$ & .550 \\
\hline Aortic surgery & $-3.5 \pm 9.9$ & $-1.0 \pm 9.5$ & .328 \\
\hline ECMO/MCS & $2.5 \pm 4.2$ & $0.4 \pm 4.4$ & .678 \\
\hline Heart transplant & $2.7 \pm 6.3$ & $0.4 \pm 4.4$ & .090 \\
\hline Other & $2.6 \pm 20.2$ & $-1.4 \pm 5.3$ & .206 \\
\hline Dates institutions halted elective cases, $\mathrm{n}(\%)$ & & & .890 \\
\hline March 1-14, 2020 & $6(27)$ & $10(22)$ & \\
\hline March 15-31, 2020 & $16(73)$ & $33(73)$ & \\
\hline April 1, 2020 onwards & 0 & $2(4)$ & \\
\hline $\begin{array}{l}\text { Required conversion of the following locations to } \\
\text { treating areas for patients with COVID-19, } \mathrm{n}(\%)\end{array}$ & & & .020 \\
\hline None & $0(0)$ & $14(31)$ & \\
\hline CSICU & $10(45)$ & $9(20)$ & \\
\hline Operating room & $6(27)$ & $3(7)$ & \\
\hline Surgical wards & $15(68)$ & $8(18)$ & \\
\hline Medical wards & $21(95)$ & $26(58)$ & \\
\hline Convention centers/public facilities & $6(27)$ & $8(18)$ & \\
\hline Ground construction of tents/buildings & $6(27)$ & $3(7)$ & \\
\hline $\mathrm{CCU}$ & $4(18)$ & $3(7)$ & \\
\hline Redeployed the following members of cardiac surgical teams, $n(\%)$ & & & .001 \\
\hline Cardiac surgeon & $13(59)$ & $4(9)$ & \\
\hline Trainee & $15(68)$ & $4(9)$ & \\
\hline $\begin{array}{l}\text { Routinely screen with COVID-19 test the following individuals } \\
\text { for COVID-19 before cardiac surgery, } \mathrm{n}(\%)\end{array}$ & & & .907 \\
\hline All cardiac surgery patients & $17(77)$ & $23(51)$ & \\
\hline All emergency cardiac surgical patients & $9(41)$ & $18(40)$ & \\
\hline Family members of cardiac surgical patients & $0(0)$ & $2(4)$ & \\
\hline \multicolumn{4}{|l|}{$\begin{array}{l}\text { Mechanism exists for patients on waiting list to seek care } \\
\text { without going to ED, } \mathrm{n}(\%)\end{array}$} \\
\hline Yes (Total) & $17(77)$ & $38(84)$ & .798 \\
\hline Of those with follow-up & & & .988 \\
\hline As needed & $15(88)$ & $33(87)$ & \\
\hline Reach out weekly/biweekly & $2(12)$ & $5(13)$ & \\
\hline Use of telemedicine during COVID-19, n (\%) & $17(77)$ & $44(98)$ & .012 \\
\hline
\end{tabular}

ICU, Intensive care unit; COVID-19, coronavirus disease 2019; $C A B G$, coronary artery bypass grafting surgery; $E C M O$, extracorporeal membrane oxygenation; $M C S$, mechanical circulatory support; $C S I C U$, cardiac surgery intensive care unit; $C C U$, cardiovascular care unit; $E D$, emergency department.

experience of outcomes of ECMO in the management of COVID-19 was associated with greater survival than some previous reports $(\mathrm{n}=131$, of which $82 \%$ still alive either decannulated or still supported). These results compare favorably with those previously reported in a systematic review and meta-analysis of patients with
COVID-19 who underwent ECMO $(\mathrm{n}=17$, of which $6 \%$ survived ${ }^{15}$ and the COVID-19 ECMO registry through the Extracorporeal Life Support Organization $(n=264$, of which 124 were discharged alive $[46 \%]),{ }^{16}$ although we are unable to elucidate any further outcomes beyond survival alone. 
Percent Decline in Cardiac Surgical Operative Volume Due to COVID-19

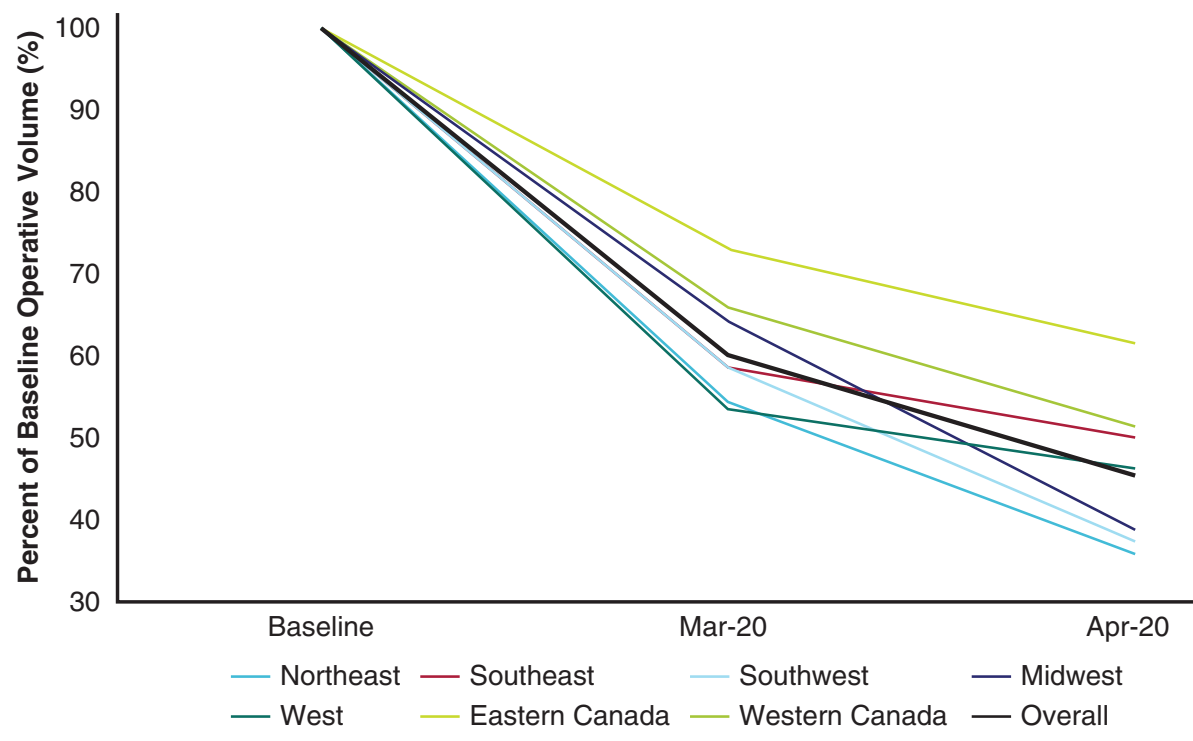

A

Percent Decline in Cardiac Surgical Operative Volume Due to COVID-19

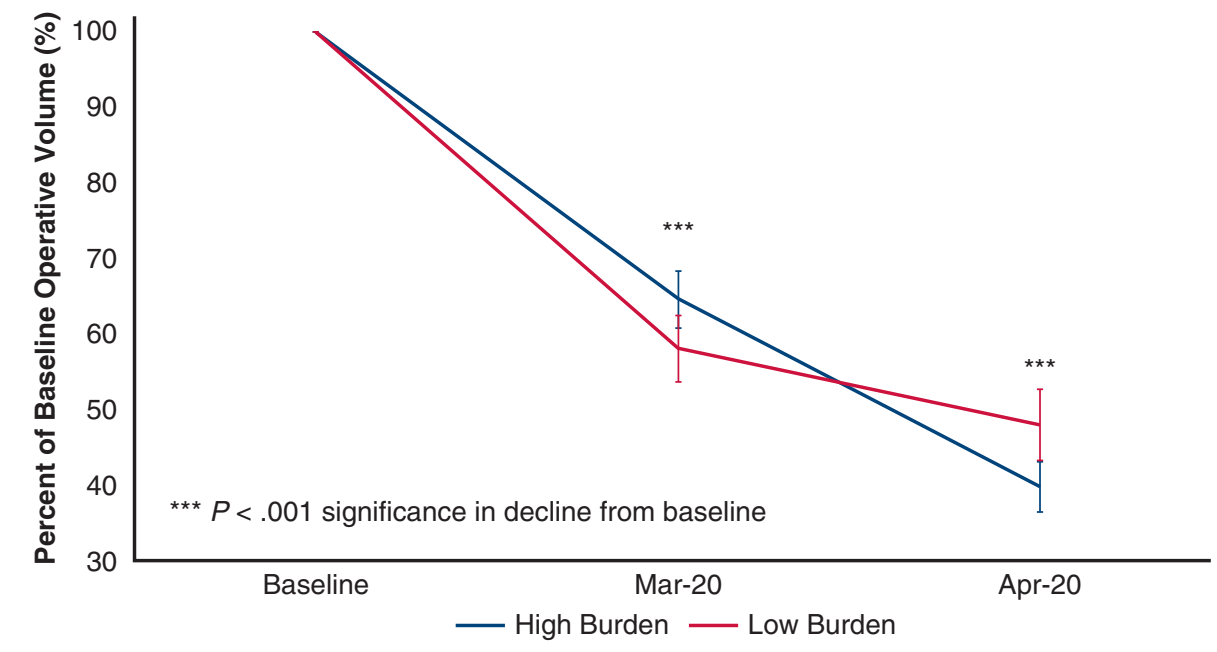

B

FIGURE 2. A, Effect of COVID-19 on adult cardiac surgery case volume stratified by North American regions; and B, high and low COVID-19 hospitalization burden. High COVID-19 burden was defined as institutions with >100 hospitalization patients with confirmed or suspected COVID-19. COVID-19, Coronavirus disease 2019.

In efforts to preserve or redirect limited resources and personnel for the treatment of patients with COVID-19, most nonurgent cardiac surgical services were deferred in a fashion that was consistent with recent Taskforce and Society guidance statements. ${ }^{1,4}$ This was consistent in the majority of cardiac surgical institutions reporting either high or low burdens of hospitalized patients with COVID-19, although regional variations did exist. Our findings of changes in cardiac surgical case mix to prioritize more urgent cases such as CABG and ECMO with COVID-19 contextualize ongoing recommendations on selection and triage of cardiac surgeries ${ }^{1,4}$ in the increasingly challenging health care situation caused by the COVID-19 pandemic.

The implications of deferred cardiac surgical operations remain unknown, however, previous studies examining deferral of cardiac surgical operations due to limited capacity has been associated with an increase in operative mortality for patients on the waiting list. ${ }^{17-19}$ The current analysis is important, given the poor outcomes with the natural history of cardiac surgical disease, such as severe aortic stenosis with reported mortality rates while awaiting surgical treatment to be as high as $3.7 \%$ at 1 month and $11.6 \%$ at 6 months, ${ }^{19}$ whereas for patients awaiting 


\section{Cardiac Surgery Case Distribution Pre and During COVID-19}

\section{Pre COVID-19}

$\mathrm{N}=5354$ cases $/$ month

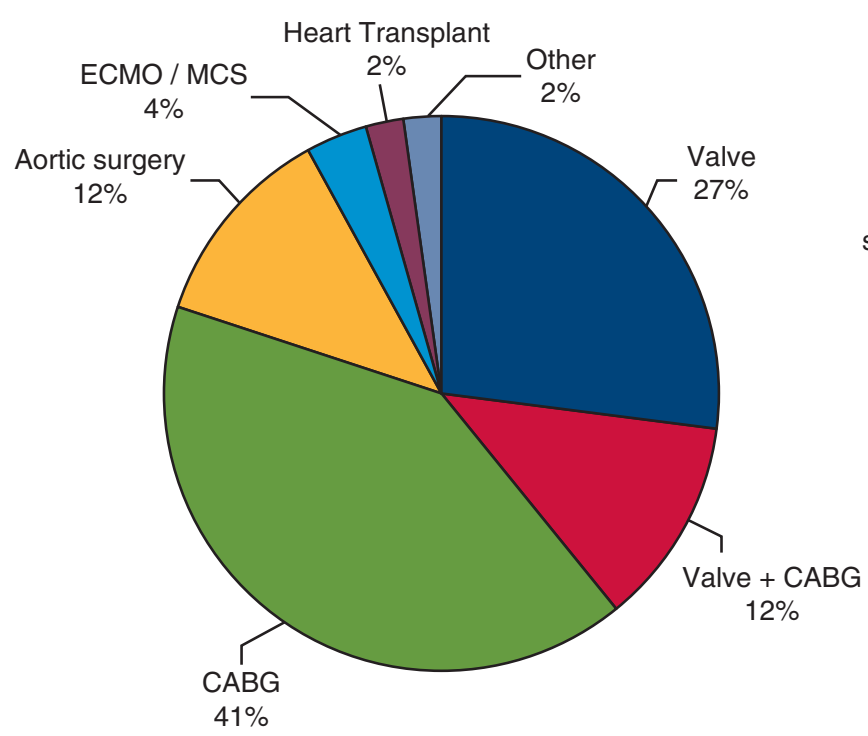

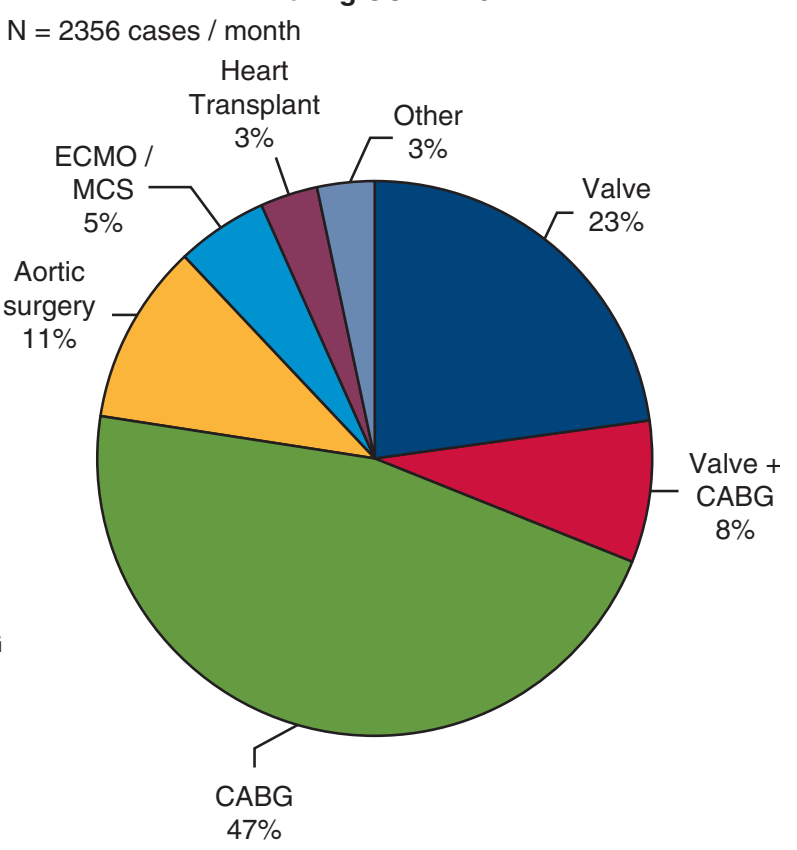

A

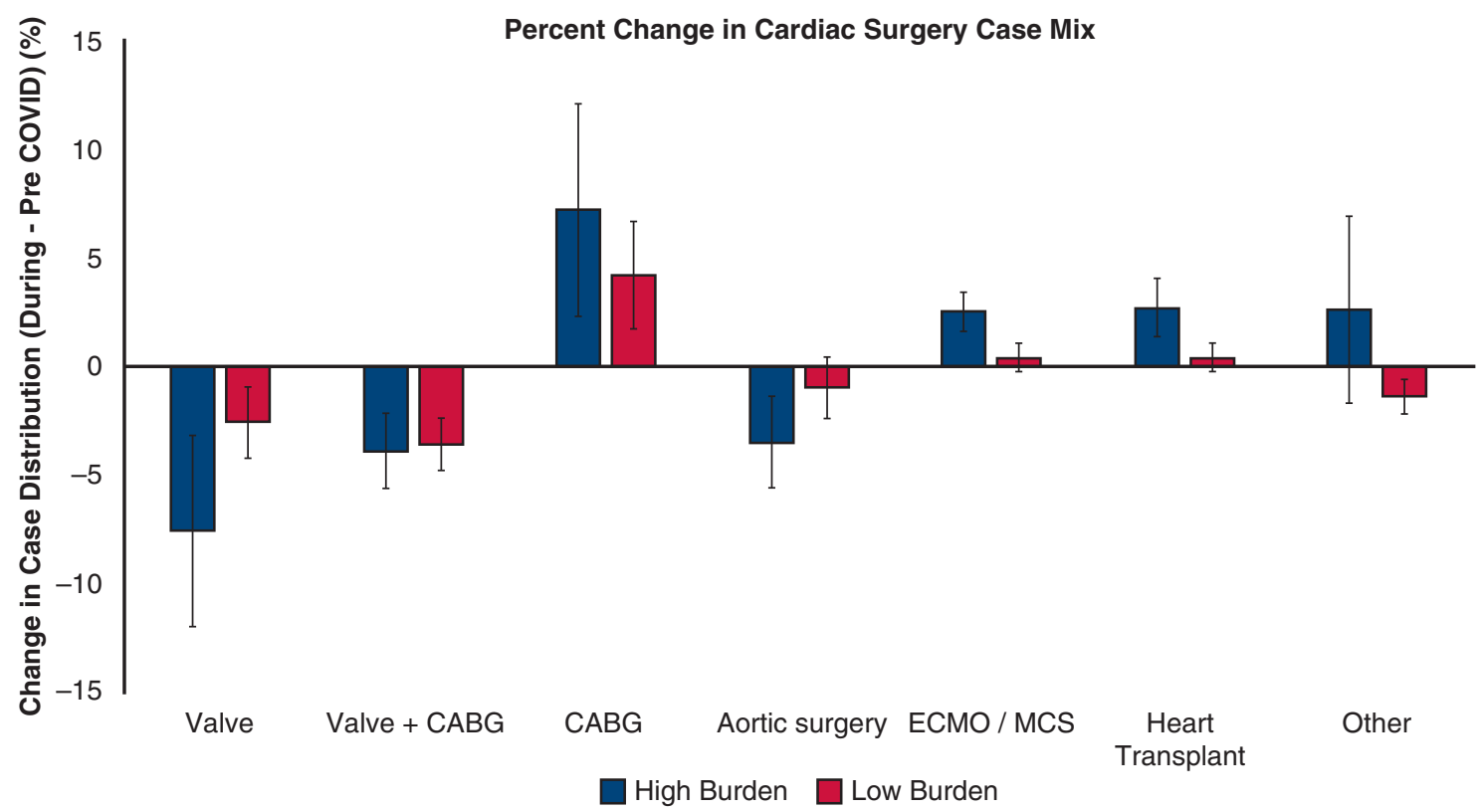

B

FIGURE 3. A, Effect of COVID-19 on cardiac surgery case mix pre- versus during the COVID-19 pandemic and; B, change in case mix when stratified by high and low COVID-19 hospitalization burden. COVID-19, Coronavirus disease 2019; ECMO, extracorporeal membrane oxygenation; MCS, mechanical circulatory support; $C A B G$, coronary artery bypass grafting.

CABG, median waiting list mortality rates can be as high as $2.6 \%$ to $11.0 \%$ per month. ${ }^{17}$

Another emerging concern of the cardiovascular community is patient reluctance to seek care at a hospital during the
COVID-19 outbreak, which has been inferred from the recent $40 \%$ reduction in patients presenting to hospital with an ST-elevation myocardial infarction (STEMI) during the COVID-19 crisis. ${ }^{20}$ Other potential reasons for reduced 


\section{Cardiac Surgery in North America and COVID-19: Regional Variability in Burden and Impact}

\section{Methods: Survey completed by 67 cardiac surgery institutions in North America}
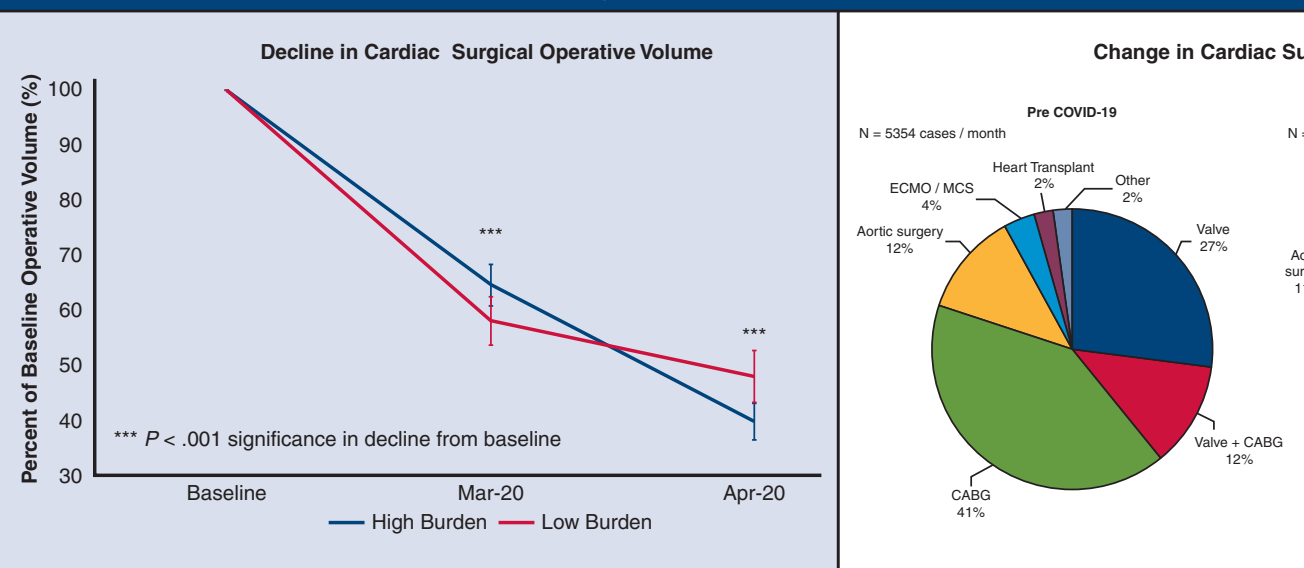

Implications: Our findings can inform institutions regarding regional and national impact of the pandemic on hospital case volume and mix to predict and prepare for the post COVID-19 surge in cardiac surgery damand

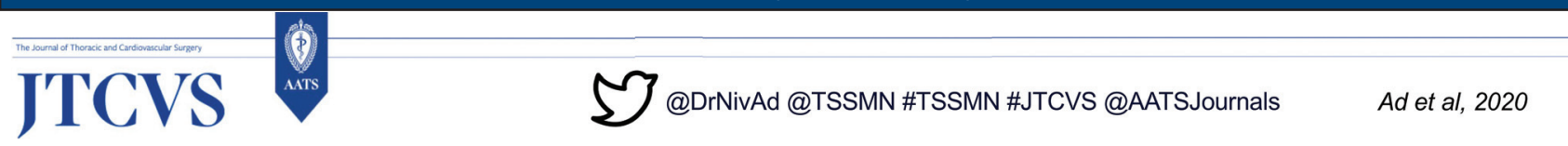

FIGURE 4. The decline in cardiac surgery case volume in North America during the COVID-19 pandemic and change in cardiac surgery case mix. COVID19, Coronavirus disease 2019; ECMO, extracorporeal membrane oxygenation; $M C S$, mechanical circulatory support; $C A B G$, coronary artery bypass grafting.

STEMI presentations could relate to altered patient behavior or psychological responses to STEMI symptoms, disrupted care pathways, or altered cardiovascular risk factors pertaining to lockdown conditions during the pandemic. ${ }^{20}$ It remains to be seen if a collateral effect of COVID-19 surge planning that has resulted in an increased number of patients being deferred will result in greater rates of perioperative morbidity and mortality. Discussions in different surgical forums already share the resurgence of conditions due to delayed presentations for cardiac surgery including, but not limited to, mechanical complications of myocardial infarction such as acute ventricular septal defect.

There is a need for intensified triage, patient counseling, empowerment, and proactive follow-up, ${ }^{21}$ with the provision of virtual emergency care triage for cardiovascular patients, ${ }^{22}$ to allow for timely evaluation without subjecting patients to unnecessary travel to the emergency department. Ultimately, with reduced access to diagnostic testing and operations, there is a concern of a surge of patients with cardiovascular disease who will require treatment. Institutions should plan for future transitions during pandemics into safe zones to allow vital services to operate with minimized disruptions to maintain the standard of care in the diagnosis and management of cardiovascular diseases-which remains a major cause of annual mortality in North America, with more than 900,000 patients deaths per year. ${ }^{3}$
Unprecedented times call for unprecedented collaboration. ${ }^{23}$ There is a need for real-time sharing of expertise and experiences ${ }^{2,24}$ and to be proactive, and contribute our skill sets, both within and outside our traditional scopes of practice where necessary. ${ }^{4,25}$ Our study provides unique information on cardiac surgical patients that can be generalized to other health conditions to assist health care policymakers and institutions in their need to not only consider methods for containing and treating these infections, but also how infection outbreaks may affect systems of care beyond the immediate infection. Furthermore, as the COVID-19 pandemic abates, appropriate strategies and system-wide adjustments are needed to increase cardiac surgical operating capacity to reduce substantial delays and increased cardiovascular patient morbidity and mortality on the waiting list-estimates include the need to perform $263 \%$ of monthly baseline volume to clear the backlog of cases in 1 month. ${ }^{11}$

\section{Limitations}

Our study is subject to response bias and relies on center self-reported data. The response rate to this survey was $40 \%$; however, the sites included represent a diverse geographic sample and a significant annual case volume. We were not made aware of specific institutional triage strategies, composition of the waiting list, and decision-making of each institution when prioritizing surgeries. Due to the small number of patients with COVID-19 who underwent 
cardiac surgeries or ECMO, we were unable to adjust for comorbidities, complications from COVID-19, stratify venoarterial versus venovenous ECMO, or describe other outcomes of these patients other than mortality at the time of the survey. We do not have data in regard to the number of patients who were referred for transcatheter aortic valve replacement instead of surgical aortic valve replacement for the purposes of reducing postoperative length of stay and perioperative risks. Our study is a snapshot of a rapidly evolving situation affecting heterogenous populations and regions with variable testing and responses due to the pandemic's impact. Participating institutions were predominantly from academic institutions and may not reflect that of community programs. Furthermore, institutions with fewer hospital beds may be proportionally more greatly affected due to limited resources, although this remains to be determined. Given the resource intensive nature of cardiac surgery and demonstrated feasibility of enhanced recovery after cardiac surgery programs ${ }^{26}$ and minimally invasive techniques ${ }^{27}$ in reducing postoperative intensive care length of stay, the utility of fast-track postoperative pathways can be a promising avenue for investigation. In addition, these pathways can potentially be further refined to conserve essential hospital resources in the COVID-19 era while maintaining the safety of our patients.

\section{CONCLUSIONS}

We describe the first comprehensive survey report of North American adult cardiac surgical experience with COVID-19 and demonstrate national and regional variations in response to COVID-19. The COVID-19 pandemic has resulted in a decline to $45 \%$ of baseline cardiac surgery case volumes as most institutions defer nonurgent operations, with changes in case mix. These findings can inform institutions and health care systems regarding the regional and national impact of the pandemic on hospital case volume and mix. The data also provide valuable information regarding the volume of patients with their procedures deferred to help government and institutions predict and prepare for the post-COVID-19 surge in cardiac surgery demand.

\section{Conflict of Interest Statement}

The authors reported no conflicts of interest.

The Journal policy requires editors and reviewers to disclose conflicts of interest and to decline handling or reviewing manuscripts for which they may have a conflict of interest. The editors and reviewers of this article have no conflicts of interest.

\section{References}

1. Haft JW, Atluri P, Alawadi G, Engelman D, Grant MC, Hassan A, et al. Adult cardiac surgery during the COVID-19 pandemic: a tiered patient triage guidance statement. Ann Thorac Surg. 2020;110:697-700.
2. Vervoort D, Ma X, Luc JGY, Zieroth S. Rapid scholarly dissemination and cardiovascular community engagement to combat the infodemic of the COVID19 pandemic. Can J Cardiol. 2020;36:969.e1-969.e2.

3. Vervoort D, Luc JGY, Percy E, Hirji S, Lee R. Assessing the collateral damage of the novel coronavirus: a call to action for the post-COVID-19 era. Ann Thorac Surg. April 30, 2020 [Epub ahead of print].

4. Hassan A, Arora RC, Adams C, Bouchard D, Cook R, Gunning D, et al. Cardiac surgery in Canada during the COVID-19 pandemic: a guidance statement from the Canadian Society of Cardiac Surgeons. Can J Cardiol. 2020;36:952-5.

5. Rubin EJ, Harrington DP, Hogan JW, Gatsonis C, Baden LR, Hamel MB. The urgency of care during the Covid-19 pandemic-learning as we go. $N$ Engl J Med. 2020;382:2461-2.

6. Guan W, Ni Z, Hu Y, Liang WH, Ou CQ, He JX, et al. Clinical characteristics of coronavirus disease 2019 in China. N Engl J Med. 2020;382:1708-20.

7. Fineberg HV. Ten weeks to crush the curve. N Engl J Med. 2020;382:e37.

8. Jones DS. History in a crisis-lessons for Covid-19. N Engl J Med. 2020;382: 1681-3.

9. Rosenbaum L. Facing Covid-19 in Italy-ethics, logistics, and therapeutics on the epidemic's front line. $N$ Engl J Med. 2020;382:1873-5.

10. Seese L, Aranda-Michel E, Sultan I, Morell VO, Mathier MA, Mulukutla SR, et al. Programmatic responses to the coronavirus pandemic: a survey of 502 cardiac surgeons. Ann Thorac Surg. April 28, 2020 [Epub ahead of print].

11. Salenger R, Etchill EW, Ad N, Matthew T, Alejo D, Whitman G, et al. The surge after the surge: cardiac surgery post-COVID-19. Ann Thorac Surg. May 3, 2020 [Epub ahead of print].

12. Gates B. Responding to Covid-19-a once-in-a-century pandemic? N Engl J Med. 2020;382:1677-9.

13. Barr J, Podolsky SH. A national medical response to crisis-the legacy of World War II. N Engl J Med. April 29, 2020 [Epub ahead of print].

14. Wood DA, Mahmud E, Thourani VH, Sathananthan J, Virani A, Poppas A, et al. Safe reintroduction of cardiovascular services during the COVID-19 pandemic: guidance from North American Society Leadership. Ann Thorac Surg. 2020;110:733-40.

15. Henry BM, Lippi G. Poor survival with extracorporeal membrane oxygenation in acute respiratory distress syndrome (ARDS) due to coronavirus disease 2019 (COVID-19): pooled analysis of early reports. J Crit Care. 2020;58:27-8.

16. Extracorporeal Life Support Organization. ECMO and ECLS $>$ Registry $>$ Full COVID-19 Registry Dashboard. Available at: https://www.elso.org/Registry/ FullCOVID19RegistryDashboard.aspx. Accessed May 10, 2020.

17. Seddon ME, French JK, Amos DJ, Ramanathan K, McLaughlin SC, White HD Waiting times and prioritization for coronary artery bypass surgery in New Zealand. Heart. 1999;81:586-92.

18. Rexius H, Brandrup-Wognsen G, Odé A, Jeppsson A. Mortality on the waiting list for coronary artery bypass grafting: incidence and risk factors. Ann Thorac Surg. 2004;77:769-74; discussion 774-5.

19. Malaisrie SC, McDonald E, Kruse J, Li Z, McGee EC Jr, Abicht TO, et al. Mortality while waiting for aortic valve replacement. Ann Thorac Surg. 2014;98:1564-71.

20. Tanner R, MacDaragh Ryan P, Caplice NM. COVID-19-Where have all the STEMIs gone? Can J Cardiol. 2020;36:1161.e9-10.

21. Percy E, Luc JGY, Vervoort D, Hirji S, Ruel M, Coutinho T. post-discharge cardiac care in the era of coronavirus 2019: how should we prepare? Can J Cardiol. 2020;36:956-60.

22. Hollander JE, Carr BG. Virtually perfect? Telemedicine for Covid-19. N Engl J Med. 2020;382:1679-81.

23. Luc J, Archer M, Arora R, Bender EM, Blitz A, Cooke DT, et al. The Thoracic Surgery Social Media Network experience during the COVID-19 pandemic. Ann Thorac Surg. May 18, 2020 [Epub ahead of print].

24. Han J, Luc J. Role of ethical guidelines in alleviating moral distress during the COVID-19 pandemic: the trainees' perspective. Ann Thorac Surg. June 5, 2020 [Epub ahead of print].

25. Luc JGY, Vervoort D, Han JJ, Sade RM. Part of the cure or spreader of disease? Ann Thorac Surg. 2020;110:359-61.

26. William JB, McConnell G, Allender JE, Woltz P, Kane K, Smith PK, et al. Oneyear results from the first US-based enhanced recovery after cardiac surgery (ERAS Cardiac) program. J Thorac Cardiovasc Surg. 2019;157:1881-8.

27. Hawkins RB, Mehaffey JH, Kessel SM, Dahl JJ, Kron IL, Kern JA, et al. Minimally invasive mitral valve surgery is associated with excellent resource utilization, cost, and outcomes. J Thorac Cardiovasc Surg. 2018;156:611-6.e3.

Key Words: coronavirus disease 2019, COVID-19, cardiac surgery, case volume, cardiovascular surgery 


\section{COLLABORATORS}

Rakesh C. Arora, MD, PhD, Section of Cardiac Surgery, Department of Surgery, Max Rady College of Medicine, University of Manitoba, St. Boniface Hospital, Winnipeg, Manitoba, Canada

Husam H. Balkhy, MD, Section of Cardiac Surgery, Department of Surgery, University of Chicago Medicine, Ill

Edward M. Bender, MD, Department of Cardiothoracic Surgery, Stanford University, Palo Alto, Calif

Daniel M. Bethencourt, MD, Division of Cardiac Surgery, Orange Coast Memorial Medical Centers, Fountain Valley, Calif

Gianluigi Bisleri, MD, Division of Cardiac Surgery, Queen's University, Kingston, Ontario, Canada

Douglas Boyd, MD, Division of Cardiothoracic Surgery, East Carolina University, Brody School of Medicine, Greenville, NC

Michael W. A. Chu, MD, Med, Division of Cardiac Surgery, Western University, London, Ontario, Canada

Kim I. de la Cruz, MD, Division of Cardiothoracic Surgery, Methodist Heart Hospital San Antonio, San Antonio, Tex

Abe DeAnda Jr, MD, Division of Cardiovascular and Thoracic Surgery, UTMB-Galveston, Galveston, Tex

Daniel T. Engelman, MD, Heart and Vascular Program,

Baystate Health, Springfield, Mass

Emily A. Farkas, MD, Division of Cardiac Surgery, ThedaCare Appleton Heart Institute, Appleton, Wis

Lynn M. Fedoruk, MD, Division of Cardiac Surgery, Royal Jubilee Hospital, Vancouver Island Health Authority, University of British Columbia, Victoria, British Columbia, Canada

Michael Fiocco, MD, Division of Cardiac Surgery, MedStar Union Memorial Hospital, Baltimore, Md

Jessica Forcillo, MD, MSc, MPH, Division of Cardiac Surgery, Université de Montréal, Department of Cardiac Surgery- Montréal University Hospital Centre (CHUM), Montreal, Quebec, Canada

Guy Fradet, MD, Division of Cardiovascular Surgery, Department of Surgery, University of British Columbia, Kelowna General Hospital, Kelowna, British Columbia, Canada

Stephen E. Fremes, MD, MSc, Schulich Heart Centre Sunnybrook Health Sciences Centre, University of Toronto, Toronto, Ontario, Canada

James S. Gammie, MD, Division of Cardiac Surgery, Department of Surgery, University of Maryland School of Medicine, Baltimore, Md

Arnar Geirsson, MD, Department of Surgery, Yale University, New Haven, Conn

Marc W. Gerdisch, MD, Department of Cardiothoracic Surgery, Franciscan Health Heart Center, Indianapolis, Ind
Leonard N. Girardi, MD, Department of Cardiothoracic Surgery, Weill Cornell Medicine, New York, NY

Clayton A. Kaiser, MD, Department of Thoracic Surgery, Vanderbilt University Medical Center, Nashville, Tenn

Tsuyoshi Kaneko, MD, Division of Cardiac Surgery, Department of Surgery, Brigham and Women's Hospital, Harvard Medical School, Boston, Mass

William D.T. Kent, MD, MSc, Section of Cardiac Surgery, Department of Cardiac Sciences, Libin Cardiovascular Institute, Cumming School of Medicine, University of Calgary, Calgary, Alberta, Canada

Kamal R. Khabbaz, MD, Division of Cardiac Surgery, Department of Surgery, Beth Israel Deaconess Medical Center and Harvard Medical School, Boston, Mass

Ali Khoynezhad, MD, PhD, Department of Cardiovascular Surgery, Memorial Heart and Vascular Institute, Memorial Care Long Beach Medical Center, Long Beach, Calif

Bob Kiaii, MD, Division of Cardiothoracic Surgery, UC Davis Medical Center, Sacramento, Calif

Richard Lee, MD, MBA, Division of Cardiothoracic Surgery, Medical College of Georgia at Augusta University, Augusta, Ga

Jean-Francois Legare, MD, Division of Cardiac Surgery, New Brunswick Heart Center, Dalhousie University, Saint John, New Brunswick, Canada

Eric J. Lehr, MD, PhD, Division of Cardiac Surgery, Swedish Heart and Vascular Institute, Seattle, Wash

Roderick G.G. MacArthur, MD, MSc, Division of Cardiac Surgery, Department of Surgery, Mazankowski Alberta Heart Institute, University of Alberta, Edmonton, Alberta, Canada

Patrick M. McCarthy, MD, Division of Cardiac Surgery, Department of Surgery, Bluhm Cardiovascular Institute, Northwestern University, Chicago, Ill

John R. Mehall, MD, Division of Cardiac Surgery, Penrose-St Francis Health Services, Colorado Springs, Colo

Walter H. Merrill, MD, Department of Cardiac Surgery, Vanderbilt University Medical Center, Nashville, Tenn

Marc R. Moon, MD, Division of Cardiothoracic Surgery, Department of Surgery, Washington University School of Medicine, Barnes-Jewish Hospital, St Louis, Mo

Maral Ouzounian, MD, PhD, Division of Cardiovascular Surgery, Peter Munk Cardiac Centre, Toronto General Hospital and University of Toronto, Toronto, Ontario, Canada

Matthias Peltz, MD, Department of Cardiovascular and Thoracic Surgery, University of Texas Southwestern Medical Center, Dallas, Tex

Louis P. Perrault, MD, PhD, Division of Cardiac Surgery, Institut de Cardiologie de Montreal, Universite de Montreal, Montreal, Quebec, Canada

Ourania Preventza, MD, MBA, Department of Cardiovascular Surgery, Texas Heart Institute; and Division of 
Cardiothoracic Surgery, Michael E. DeBakey Department of Surgery, Baylor College of Medicine, Houston, Tex

Mahesh Ramchandani, MD, Department of Cardiothoracic Surgery, DeBakey Heart and Vascular Center, Houston Methodist Hospital, Houston, Tex

Basel Ramlawi, MD, MSc, Department of Cardiothoracic Surgery, Valley Health System - Heart and Vascular Center, Winchester Medical Center, Winchester, Va

Rawn Salenger, MD, Division of Cardiac Surgery, Department of Surgery, University of Maryland School of Medicine, Baltimore, Md

Michael E. Sekela, MD, Division of Cardiothoracic Surgery, Department of Surgery, University of Kentucky, Lexington, $\mathrm{Ky}$

Frank W. Sellke, MD, Division of Cardiothoracic Surgery, Department of Surgery, Cardiovascular Research Center, Rhode Island Hospital, Alpert Medical School of Brown University, Providence, RI

John M. Stulak, MD, Department of Cardiovascular Surgery, Mayo Clinic, Rochester, Minn

Francis P. Sutter, MD, Division of Cardiac Surgery, Lankenau Medical Center, Wynnewood, $\mathrm{Pa}$
Tomasz A. Timek, MD, PhD, Division of Cardiothoracic Surgery, Spectrum Health, Michigan State University College of Human Medicine, Grand Rapids, Mich

Glenn Whitman, MD, Division of Cardiac Surgery, Department of Surgery, Johns Hopkins University School of Medicine, Baltimore, Md

Judson B. Williams, MD, MHS, Department of Cardiovascular and Thoracic Surgery, WakeMed Health and Hospitals, Raleigh, NC

Daniel R. Wong, MD, MPH, Division of Cardiac Surgery, Department of Surgery, University of British Columbia, Royal Columbian Hospital, New Westminster, British Columbia, Canada

Bobby Yanagawa, MD, PhD, Division of Cardiac Surgery, St. Michael's Hospital, University of Toronto, Toronto, Ontario, Canada

Jian Ye, MD, MSc, Division of Cardiovascular Surgery, Department of Surgery, University of British Columbia, St Paul's Hospital, Vancouver, British Columbia, Canada

Sanford M. Zeigler, MD, Division of Cardiothoracic Surgery, Department of Surgery, Medical University of South Carolina, Charleston, SC 
TABLE E1. Participating institutions

\begin{tabular}{|c|c|c|c|c|}
\hline Number & Hospital & City & State/province & Country \\
\hline 1 & Mazankowski Alberta Heart Institute, University of Alberta & Edmonton & Alberta & Canada \\
\hline 2 & Foothills Medical Centre, University of Calgary & Calgary & Alberta & Canada \\
\hline 3 & Royal Columbia Hospital, University of British Columbia & Vancouver & British Columbia & Canada \\
\hline 4 & Vancouver General Hospital, University of British Columbia & Vancouver & British Columbia & Canada \\
\hline 5 & St Paul's Hospital, University of British Columbia & Vancouver & British Columbia & Canada \\
\hline 6 & Kelowna General Hospital, University of British Columbia & Kelowna & British Columbia & Canada \\
\hline 7 & Royal Jubilee Hospital, University of British Columbia & Victoria & British Columbia & Canada \\
\hline 8 & University of Manitoba & Winnipeg & Manitoba & Canada \\
\hline 9 & QEII Health Sciences Centre, Dalhousie University & Halifax & Nova Scotia & Canada \\
\hline 10 & Toronto General Hospital, University of Toronto & Toronto & Ontario & Canada \\
\hline 11 & St Michael Hospital, University of Toronto & Toronto & Ontario & Canada \\
\hline 12 & Sunnybrook Health Sciences Centre, University of Toronto & Toronto & Ontario & Canada \\
\hline 13 & London Health Sciences Center, Western University & London & Ontario & Canada \\
\hline 14 & Ottawa Heart Institute, Ottawa University & Ottawa & Ontario & Canada \\
\hline 15 & Queens University & Kingston & Ontario & Canada \\
\hline 16 & University of Montreal Hospital Centre (CHUM) & Montreal & Quebec & Canada \\
\hline 17 & Montreal Heart Institute & Montreal & Quebec & Canada \\
\hline 18 & University of Alabama & Birmingham & Alabama & USA \\
\hline 19 & Cedars-Sinai Medical Center & Los Angeles & California & USA \\
\hline 20 & Memorial Care Long Beach Medical Center & Los Angeles & California & USA \\
\hline 21 & Northbay Healthcare & Fairfield & California & USA \\
\hline 22 & The Bethencourt Group & Long Beach & California & USA \\
\hline 23 & University of California Davis & Davis & California & USA \\
\hline 24 & Centura Health & Colorado Springs & Colorado & USA \\
\hline 25 & Yale New Haven Medical Center & New Haven & Conneticut & USA \\
\hline 26 & University of Miami & Miami & Florida & USA \\
\hline 27 & Emory University & Atlanta & Georgia & USA \\
\hline 28 & Medical College of Georgia at Augusta University & Augusta & Georgia & USA \\
\hline 29 & Northwestern University & Chicago & Illinois & USA \\
\hline 30 & University of Chicago & Chicago & Illinois & USA \\
\hline 31 & Franciscan Health Indianapolis & Indianapolis & Indiana & USA \\
\hline 32 & University of Kentucky & Lexington & Kentucky & USA \\
\hline 33 & Baystate Medical Center & Springfield & Massachusetts & USA \\
\hline 34 & Brigham and Women's Hospital, Harvard Medical School & Boston & Massachusetts & USA \\
\hline 35 & Beth Israel Deaconess Medical Center & Boston & Massachusetts & USA \\
\hline 36 & Washington Adventist Hospital & Takoma Park & Maryland & USA \\
\hline 37 & UM Saint Joseph Medical Center & Towson & Maryland & USA \\
\hline 38 & University of Maryland Medical Center & Baltimore & Maryland & USA \\
\hline 39 & Union Memorial Hospital & Baltimore & Maryland & USA \\
\hline 40 & John Hopkins Hospital & Baltimore & Maryland & USA \\
\hline 41 & Spectrum Health/Michigan State University & Grand Rapids & Michigan & USA \\
\hline 42 & Mayo Clinic & Rochester & Minnesota & USA \\
\hline 43 & Washington University School of Medicine St. Louis & St. Louis & Missouri & USA \\
\hline 44 & East Carolina University, Brody School of Medicine & Greenville & North Carolina & USA \\
\hline
\end{tabular}


TABLE E1. Continued

\begin{tabular}{|c|c|c|c|c|}
\hline Number & Hospital & City & State/province & Country \\
\hline 45 & WakeMed Health and Hospitals & Raleigh & North Carolina & USA \\
\hline 46 & Lenox Hill Hospital & New York & New York & USA \\
\hline 47 & New York Hospital - Weill Cornell Medical Center & New York & New York & USA \\
\hline 48 & Mount Sinai Hospital & New York & New York & USA \\
\hline 49 & Starr-Wood Cardiac Group & Portland & Oregon & USA \\
\hline 50 & Stanford University Good Samaritan Hospital & Corvalis & Oregon & USA \\
\hline 51 & University of Pennsylvania & Philadelphia & Pennsylvania & USA \\
\hline 52 & Main Line Health & Wynnewood & Pennsylvania & USA \\
\hline 53 & Brown Medical School Rhode Island Hospital & Providence & Rhode Island & USA \\
\hline 54 & Medical University of South Carolina & Charleston & South Carolina & USA \\
\hline 55 & Vanderbilt University & Nashville & Tennessee & USA \\
\hline 56 & Saint Thomas Heart - Ascension Saint Thomas West Hospital & Nashville & Tennessee & USA \\
\hline 57 & Houston Methodist Hospital & Houston & Texas & USA \\
\hline 58 & Texas Heart Institute, Baylor College of Medicine & Houston & Texas & USA \\
\hline 59 & University of Texas Memorial Hermann Medical Center & Houston & Texas & USA \\
\hline 60 & University of Texas Southwestern Medical Center at Dallas & Dallas & Texas & USA \\
\hline 61 & University of Texas Medical Branch Hospital & Galveston & Texas & USA \\
\hline 62 & University of Texas San Antonio & San Antonio & Texas & USA \\
\hline 63 & Methodist Healthcare System & San Antonio & Texas & USA \\
\hline 64 & Valley Health System & Winchester & Virginia & USA \\
\hline 65 & University of Virginia & Charlottesville & Virginia & USA \\
\hline 66 & Swedish Heart and Vascular Institute & Seattle & Washington & USA \\
\hline 67 & ThedaCare Appleton Heart Institute & Appleton & Wisconsin & USA \\
\hline
\end{tabular}

